\title{
FLINT COMPLEX OF THE MARIUPOL BURIAL GROUND
}

\author{
(C) 2016
}

A.V. Kolesnik, candidate of historical sciences, associate professor of the Chair of Historiography, Source Studies, Archeology and Methods of Teaching History Donetsk National University, Donetsk (Donetsk People's Republic)

Abstract. The Mariupol burial ground is one of the largest Neolithic sites of Eastern Europe. The funeral complex consists of 124 burials many of which include rich grave goods. Flint artifacts, usually single plate-like flint knives, have been found in 40 graves. In burials there also were end and oval scrapers, microlithics, axes, triangular arrowheads with bilateral treatment. The industry has been based on squeezing plates of average size. Flint tools were selected specially for burial. Flint artifacts have only been found in graves with other grave goods. In some graves there were rather numerous congestions of flint tools - from 10 to 25 tools and their workpieces. In these backpack sets plates and tools made of them also prevail. Backpack sets of the Mariupol burial ground are divided into two types. The first type includes mainly unspecialized stone tools. Backpack sets of the second type consist of stone tools and household objects, i.e. jewelry made of bone, shells and stone, ochre. The trapezes and plates were used as arrowheads and their parts. Two flint axes with polished edges are found in one of the burials. The flint industry of the Mariupol burial ground is comparable to the industry of a Neolithic layer of the Kalmius settlement in Mariupol on the opposite right river bank. Probably, the burial ground has been made by residents of the settlement. Flint products are found both in male and in female burials.

Keywords: Mariupol' burial ground; neolithic; chalcolithic; flint industry; tool kits; quiver kits; north-eastern Azov Sea coast; microlithic; sets of prestigious property; property differentiation; head of arrows; production complexes.

УДК 902.413(470.55)

\section{НЕОЛИТИЧЕСКИЙ КОМПЛЕКС СТОЯНКИ КЕДРОВЫЙ МЫС-1}

(C) 2016

\author{
В.С. Мосин, доктор исторических наук, директор \\ Южно-Уральский филиал Института истории и археологии УрО РАН, Челябинск (Россия) \\ Е.С. Яковлева, научный сотрудник \\ Археологический научный центр, Челябинск (Россия)
}

\begin{abstract}
Аннотащия. В статье публикуются предварительные итоги исследования многослойной стоянки Кедровый мыс-1 на озере Малое Миассово в Южном Зауралье. Стоянка, представлявшая собой место недолговременного обитания древнего населения, исследована полностью. Следов конструкций не обнаружено, но планиграфическим методом по распространению находок установлены приблизительные контуры жилища, вероятно, легкой шалашеобразной постройки, не оставившей следов. Из комплекса находок, представляющих эпохи камня и металла, выделена группа артефактов неолитического периода истории, установлена культурная принадлежность и относительная хронология представленного комплекса. Реконструированы сосуды козловской, полуденской и боборыкинской традиций, пополнив корпус имеющихся источников новыми данными, что, несмотря на накопленные материалы зауральского неолита, представляется по-прежнему актуальной задачей для территории Южного Зауралья, более скудно представленного керамикой, особенно археологически целыми сосудами, в сравнении с прилежащими территориями. Также рассматриваются некоторые методические аспекты проведенных полевых исследований, связанные с попыткой стратиграфического и планиграфического выделения неразрушенного неолитического слоя, что, в силу специфики геоморфологических условий региона, традиционно входит в число наиболее затруднительных задач археологических исследований в горнолесной зоне Южного Зауралья.

Ключевые слова: Южное Зауралье; горно-лесная зона; неолит; стоянка; Кедровый мыс-1; каменный инвентарь; пластинчатая индустрия; керамика; сосуды; козловская традиция; полуденская традиция; боборыкинская традиция; морфология; орнаментация; стратиграфия; планиграфия; методика; полевые исследования.
\end{abstract}

Стоянки каменного века, расположенные на берегах озер центральной части Урала (Среднее и Южное Зауралье), исследуются уже более 100 лет. Среди исследователей, внесших свой вклад в их изучение, особенно территории Южного Урала, стоят имена Н.П. Кипарисовой, К.В. Сальникова, Г.Н. Матюшина, Л.Я. Крижевской [1, с. 5-10].

Проведенный не так давно анализ имеющихся материалов позволил сделать ряд выводов и обозначить основные проблемы в изучении этого своеобразного типа археологических памятников [2]. Одной из проблем в изучении стоянок позднего неолита Зауралья является почти полное отсутствие комплексов, стра- тиграфически достоверно включающих керамику и каменный инвентарь. Большей частью характеристика этого периода дается по типологически выделенным из смешанных слоев коллекциям керамики, принадлежащим полуденской традиции декорирования. Памятники, в которых комплексы керамики козловской или полуденской традиций Зауралья сочетались бы с каменным инвентарем, единичны [3; 4, c. 212]. Сложность изучения озерных стоянок заключается в отсутствии ярко выраженной стратиграфии культурных отложений, поскольку берега предгорных озер центральной части Урала в течение нескольких тысячелетий использовались как места для 
сезонного проживания отдельных коллективов неолитического и энеолитического населения, а затем и носителей культурных традиций эпохи металла, в то время как медленные процессы почвообразования в данном регионе не позволяли культурным напластованиям избегать смешения [5, с. 231-233]. Основной задачей данной работы является публикация новейших материалов, полученных в последние годы при исследовании стоянки Кедровый мыс-1, которые позволяют с определенной долей уверенности выделить комплекс артефактов характерной для Зауралья полуденской традиции.

Стоянка Кедровый мыс-1 расположена в горнолесной зоне Южного Зауралья, на площадке в основании мыса Кедровый полуострова (острова) Сайма, разделяющего озера Большое и Малое Миассово. Относительно горизонтальная в южной части и наклонная в северной площадка памятника занимает участок между двумя каменными грядами. Северная часть выходит к скалистому обрыву берега, на несколько метров возвышающемуся над урезом воды, южная - к заболоченной полосе вдоль юго-западного края острова. Площадь раскопа составила $250 \mathrm{M}^{2}$, охватив практически всю площадку памятника. Культурный слой разбирался одновременно на всей площади раскопа зачистками с применением ножей, совочков и шпателей. Все находки фиксировались индивидуально в трех координатах; кроме того, отработанный грунт просеивался.

Обобщенно стратиграфия стоянки представлена следующей последовательностью слоев: дерн - 510 см без находок; темная гумусированная супесь или суглинок - 10 см с артефактами раннего железного века и средневековья иткульского, гамаюнского, бакальского и кушнаренковского облика; слой желто-серой или желто-коричневой супеси или суглинка с вкраплениями гумуса (пестроцвет) - 15-25 см, вмещал в себя перемешанные находки неолита и энеолита; сохранившийся отдельными пятнами, в основном по краям площадки, слой ярко-желтого или желто-коричневого суглинка с комплексом артефактов позднего неолита - 5-15 cм; материк - желтая глина, рухляк или скала.

В слоях каменного века каких-либо остатков сооружений обнаружить не удалось, что, по-видимому, связано как с геоморфологией площадки, так и с непродолжительностью жизнеобитания на ней. Планиграфия распространения находок показывает, что наиболее активно использовалась северная часть площадки, приуроченная к берегу озера. Здесь наблюдается утолщение культурного слоя и сосредоточение находок, большей частью в перемешанном слое. Только по краям этой площадки сохранились неповрежденными участки неолитического слоя.

Коллекция памятника составляет 14015 экз. находок, из которых каменная индустрия нео-, энеолитического времени, а также изделия из некремнистых пород камня - 6335 экз.; 7680 экз. - фрагменты керамики различных эпох: около 1300 фрагментов относятся к неолитическому периоду, около $3400-$ к энеолитическому, 2980 - керамика раннего железного века и средневековья, а также неопределимые фрагменты. Также 3482 фрагмента керамики собраны в просеве; размер до 1 см и отсутствие орнамента не позволили уверенно соотнести их с каким-либо хронологическим комплексом стоянки.

Коллекция изделий из камня неолитического слоя составила 621 экз. [6]. Нуклеусы (рис. 1, 1-3) - 8 экз.; один - одноплощадочный на плитке, со скошенной площадкой; три нуклеуса конические; один - торцово-фронтальный, со скошенной площадкой; два нуклеуса в обломках. Один пренуклеус на плитке фтанитоида.

Пластины без обработки - 214 экз., среди них: целые - 33 экз., проксимальные - 75 экз., медиальные 60 экз., дистальные - 46 экз. Пластины с ретушью 49 экз., (рис. 1, 4-7) среди них: пластинки с ретушью по одному краю со спинки - 14 экз., пластинки с ретушью по двум краям со спинки - 14 экз., пластинка с притупленной спинкой - 1 экз., с ретушью по одному краю с брюшка - 5 экз., по двум краям с брюшка - 1 экз., с противолежащей ретушью со спинки и брюшка - 1 экз., по двум краям со спинки и брюшка - 2 экз. В семи случаях присутствует крутая и полукрутая ретушь, на остальных пластинках мелкая краевая обработка. Пластины с ретушью утилизации 9 экз. Следы работы фиксируются как отдельные нерегулярные фасетки, заломы и зазубренность по краям пластинок.

Резцы угловые (рис. 1, 8,9) - 7 экз., среди них: с одним резцовым сколом - 6 экз., с двумя лезвиями 1 экз. Два резца на продольных сколах. Пластинки с выемками - 2 экз. Неглубокие выемки оформлены крутой ретушью со спинки. Геометрические микролиты (рис. 1, 15) - 1 экз. представлены обломком или заготовкой асимметричной трапеции или треугольника. Длинная скошенная грань оформлена крутой ретушью со спинки, короткая - без ретуши. Пластина с обработанным крутой ретушью торцом и мелкой ретушью по двум краям со спинки. Острия (рис. 1, 16-18) - 7 экз., из них 3 экз. - на микропластинках с притупленной вертикальной ретушью спинкой и выведенным на острие необработанным краем; 5 экз. симметричные, среди которых одно образовано крутой ретушью со спинки, другое ретушью со спинки и брюшка, два - ретушью с брюшка. Одно острие на тонком мелком отщепе с ретушью по двум краям со спинки. Сверла - 3 экз. на пластинах с рабочим лезвием, обработанным характерной ретушью и разворотом рабочего края. Развертки (перфораторы) 2 экз. с характерной противолежащей ретушью на верхней части пластинки возле ударного бугорка. Наконечники стрел (рис. 1, 10-12, 14) - 6 экз. Два экземпляра - на пластинах: один целый, с обработанными со спинки и брюшка плоской приостряющей ретушью пером и насадом; другой с обломанным пером, обработанным крутой ретушью со спинки и плоской ретушью с брюшка и насадом, оформленным плоской прилежащей ретушью. Двустороннеобработанные наконечники - 4 экз. Один почти целый, только с обломившимся кончиком пера, два обломка пера и часть тела наконечника с насадом. Скребки концевые (рис. 1, 20) - 17 экз. на средних и удлиненных проксимальных и медиальных сечениях, рабочий край прямой -9 экз., округлой -5 экз. и скошенной 3 экз. формы. Один скребок дублированный, один выполнен на продольном сколе с нуклеуса (рис. 1, 19). Дополнительную подработку ретушью по одно- 
Мосин В.С., Яковлева Е.С.

Неолитический комплекс стоянки Кедровый мыс-1

07.00.00 - исторические науки и археология

му краю со спинки имеют 7 экз., по одному краю с брюшка - 1 экз.; по двум краям со спинки - 5 экз., подработка прилежащей ретушью - 1 экз.

Скребки на отщепах (рис. 1, 21, 22) - 6 экз. Формы скребков подчинены конфигурации отщепов - заготовок, среди них: концевой - 1 экз., концевойбоковой -2 экз., боковые -3 экз., один из них выполнен на вертикальном сколе с нуклеуса. Ретушеры
- 2 экз. с рабочим краем, содержащим характерные заломы и смятости. Отщепы с ретушью - 9 экз. Деревообрабатывающие орудия - две заготовки небольших топориков, а также три скола со шлифованных орудий. Отбойник на крупной кварцитовой гальке с характерными забитыми краями и сколами с поверхности. Абразивы - 5 экз. на плитках песчаника, сланца, хлорита.
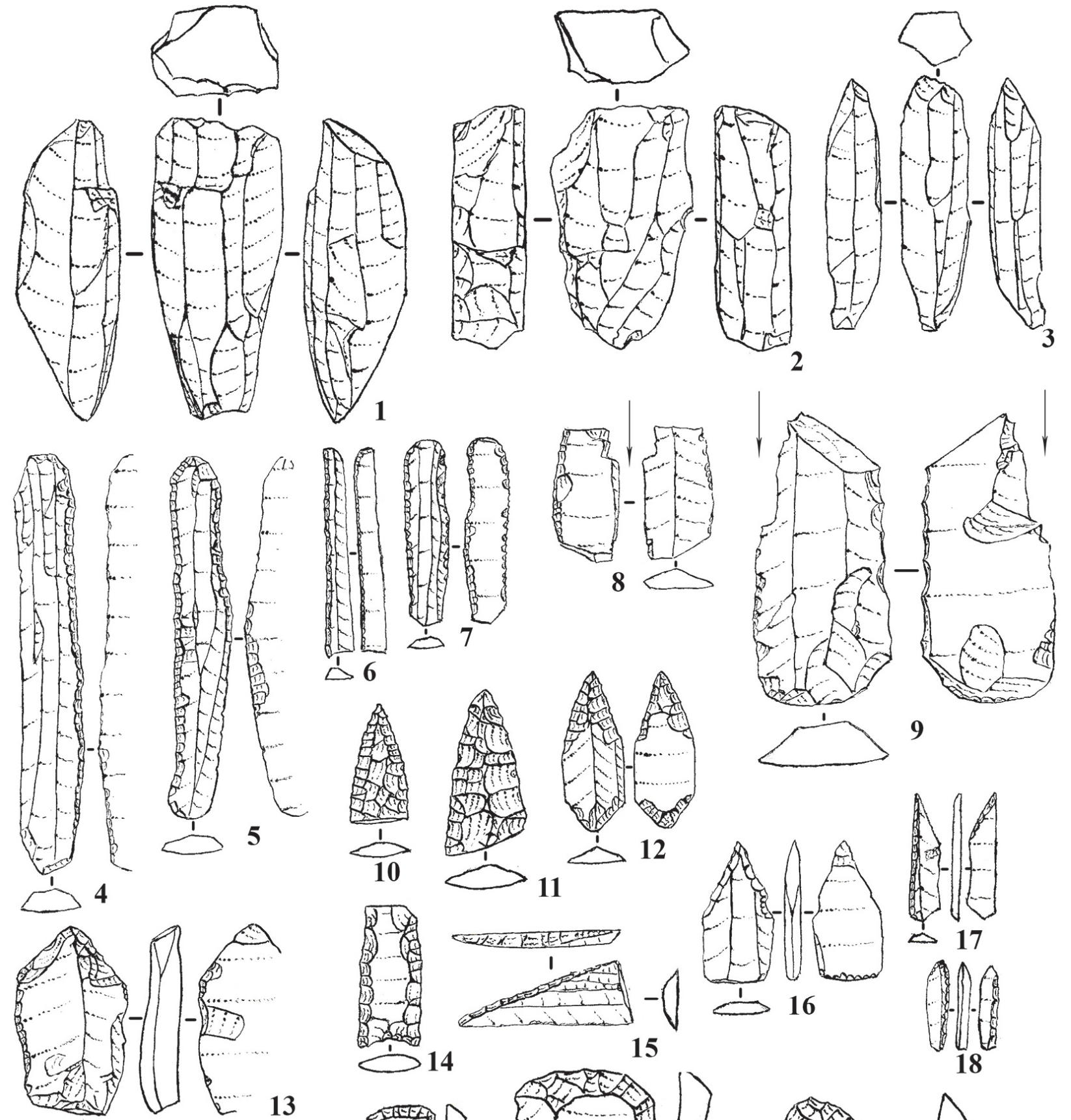

14

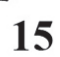

13
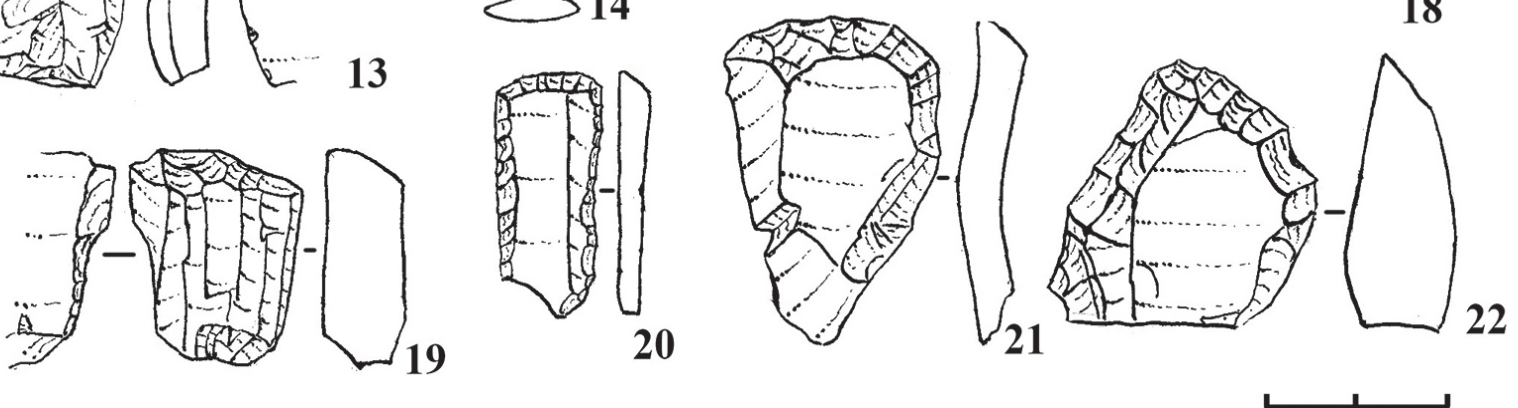

Рисунок 1 - Каменный инвентарь неолитического комплекса стоянки Кедровый мыс-1

Отходы производства орудий, представленные отщепами и чешуйками, составляют 91 экз. из халце- дона $(36,3 \%), 132$ из фтанитоидов и яшм (53\%), $26-$ сланец $(10,4 \%), 1-$ кварцит, 1 - горный хрусталь. Все 
нуклеусы выполнены на плитках фтанитоидов, за исключением одного аморфного и обломка, которые изготовлены из халцедона. Пластины почти все, за редким исключением, - из фтанитоидов и яшм. Среди орудий из халцедона выполнены отдельные отщепы с ретушью, две пластинки с ретушью, остальные орудия из фтанитоидов и яшм.

Комплекс изделий из камня неолитического слоя демонстрирует характерный для зауральского неолита пластинчатый характер индустрии [6]. Общее количество пластин - 303 экз. - почти втрое превышает общее число отщепов - 104 экз. Количество орудий на пластинах (35) также превышает число орудий на отщепах (13) почти втрое; 30\% пластин являются орудиями и вкладышами, среди отщепов доля орудий от общего числа составляет 13\%. Преобладающие параметры ширины пластин находятся в диапазоне 0,8-1,2 см; для пластин без обработки наиболее частый параметр - 0,8 см, для орудий 1-1,2 см. В половине случаев пластины обработаны по спинке - по одному и двум краям в равной степени, с преобладанием мелкой краевой ретуши. Набор орудий комплекса отражает весь спектр хозяйственной деятельности обитателей стоянки.

Керамический комплекс эпохи неолита представлен 1300 фрагментами, из которых по венчикам и реконструируемым формам (31 шт.) выделены 36 сосудов. Не соотнесенными с теми или иными сосудами остались около полусотни фрагментов, составляя не более 5\% неолитического комплекса. В целом керамический комплекс немногочислен, особенно в сравнении с памятниками Среднего Зауралья, что является характерной особенностью южноуральских неолитических памятников $[7$, с. 86; 8]; тем не менее полученные материалы хорошо отражают и дополняют сумму знаний о культурно-историческом содержании эпохи региона.

По технике декорирования коллекцию керамики неолитического слоя можно разделить на две традиции: прочерченно-накольчатую (козловскую) и гребенчато-прочерченную (полуденскую). К козловской традиции [9; 10] можно отнести 16 сосудов с прочерченно-накольчатой орнаментацией (рис. 2, 1-3), среди которых выделяются: 5 сосудов с прочерчиванием приостренной или двузубой палочкой, два неорнаментированных (отнесены в группу по сходному составу теста), 4 сосуда со смешанной техникой: прочерчивание, отступающие наколы треугольной формы, оттиски гребенчатого штампа. Орнаментальная схема проста и связана с горизонтальным зонированием, состоит из прямых либо волнистых линий. Срез венчика нередко орнаментирован наколами, насечками, вдавлениями; также в половине случаев наблюдается орнаментация сосудов с внутренней стороны венчика волнистым прочерчиванием или наколами. Форма сосудов закрытая, округлодонная; наплывы как треугольные, сглаженные или хорошо выраженные. В тесте визуально фиксируются песок и дресва, возможно, являются естественными примесями глины, реже - тальк; поверхность большинства сосудов шероховатая. Немаловажно, что сосуды данной группы очень сильно фрагментированы: для 6 сосудов не удалось восстановить профиль и приблизительный диаметр, еще 6 реконструированы только на треть верхней части, 3 - на две трети высоты, и только один - полностью. Неудовлетворительная сохранность керамики данной группы в сравнении с другими сосудами не является решающим аргументом в пользу ее большей древности, но, ввиду отсутствия строго датирующих маркеров, этот факт необходимо принимать во внимание.

Полуденский комплекс $[1 ; 11]$ представлен 14 сосудами (рис. 2, 4-7). Принципиально важно отметить, что остатки нескольких сосудов полуденской традиции вместе с каменным инвентарем были зафиксированы в сохранившихся неолитических слоях или же залегали прямо на скале. Сохранность сосудов этого комплекса значительно лучше, чем козловских: развалы крупных форм насчитывают сотни фрагментов; 8 сосудов реконструированы полностью, 5 - наполовину или две трети. Тесто сосудов с примесью талька, иногда с очень крупными фракциями, поверхность сосудов гладкая. Среди форм сосудов данной традиции можно выделить как крупные яйцевидные, так и прямостенные. Встречены миниатюрные сосудики открытой формы. О форме дна можно говорить как о предположительно круглодонной, три сосуда имеют конусовидные или близкие к ним очертания донцев.

Среди орнаментальных типов гребенчатых сосудов можно отметить: 2 прочерченно-гребенчатых, покрытых следами «шагающей» гребенки и прочерчивания палочкой с широким концом; 10 волнистогребенчатых, орнаментированных преимущественно движущимся гребенчатым штампом в техниках прочерчивания, отступания, «шагания»; 2 сосуда, покрытых только оттисками гребенчатого штампа. Coсуды «гребенчатого неолита» часто относят к финальным стадиям неолита, однако последние исследования по хронологии уральского неолита показывают синхронность «классических» полуденских форм и штампованной керамики [12], поэтому можно говорить о штампованных сосудах данной группы как о варианте единой гребенчатой традиции в рамках одного социума. В целом орнаментальная схема полуденских сосудов усложненная в сравнении с козловской: чередование прочерчивания гребенкой с оттисками или «шаганием» штампа, наклонных и горизонтальных оттисков для штампованных сосудов, у миниатюрных сосудов горизонтальная орнаментальная схема дополняется или сменяется вертикальной.

Несмотря на различия в орнаментации сосудов козловско-полуденской традиции, морфология их довольно однообразна и отражает общие черты для керамики зауральского неолита; орнаментальное разнообразие, напротив, соответствует представлению о стадиальном развитии и территориальных типах. Хронологически эти группы керамики могут быть как разновременными, так и очень близкими на временной оси, попадая в период сосуществования прочерченно-накольчатых и прочерченно-гребенчатых традиций [12]; говорить точнее, не имея закрытых датирующих комплексов, невозможно.

Также к комплексу позднего неолита относятся два сосуда боборыкинской традиции (рис. 2, 8), для которой характерен накольчатый и прочерченнонакольчатый орнамент, вертикальная или диагональная ориентация орнамента, в том числе и скрещивающиеся линии [13]. Кроме того, два миниатюрных 
Мосин В.С., Яковлева Е.С.

Неолитический комплекс стоянки Кедровый мыс-1

сосудика со специфическим, сильно запесоченным тестом, возможно, отражают связи с лесостепной зоной Западной Сибири $[14 ; 15]$. Коллекция изделий из камня из смешанного слоя составила 5940 экз. и по набору практически повторяет ассортимент неолитического времени, за исключением большего количе- ства крупных пластин, двусторонне обработанных орудий и изделий из некремнистых пород камня. Такое содержание коллекции полностью соответствует ранее изученным комплексам из смешанных слоев озерных стоянок [4].
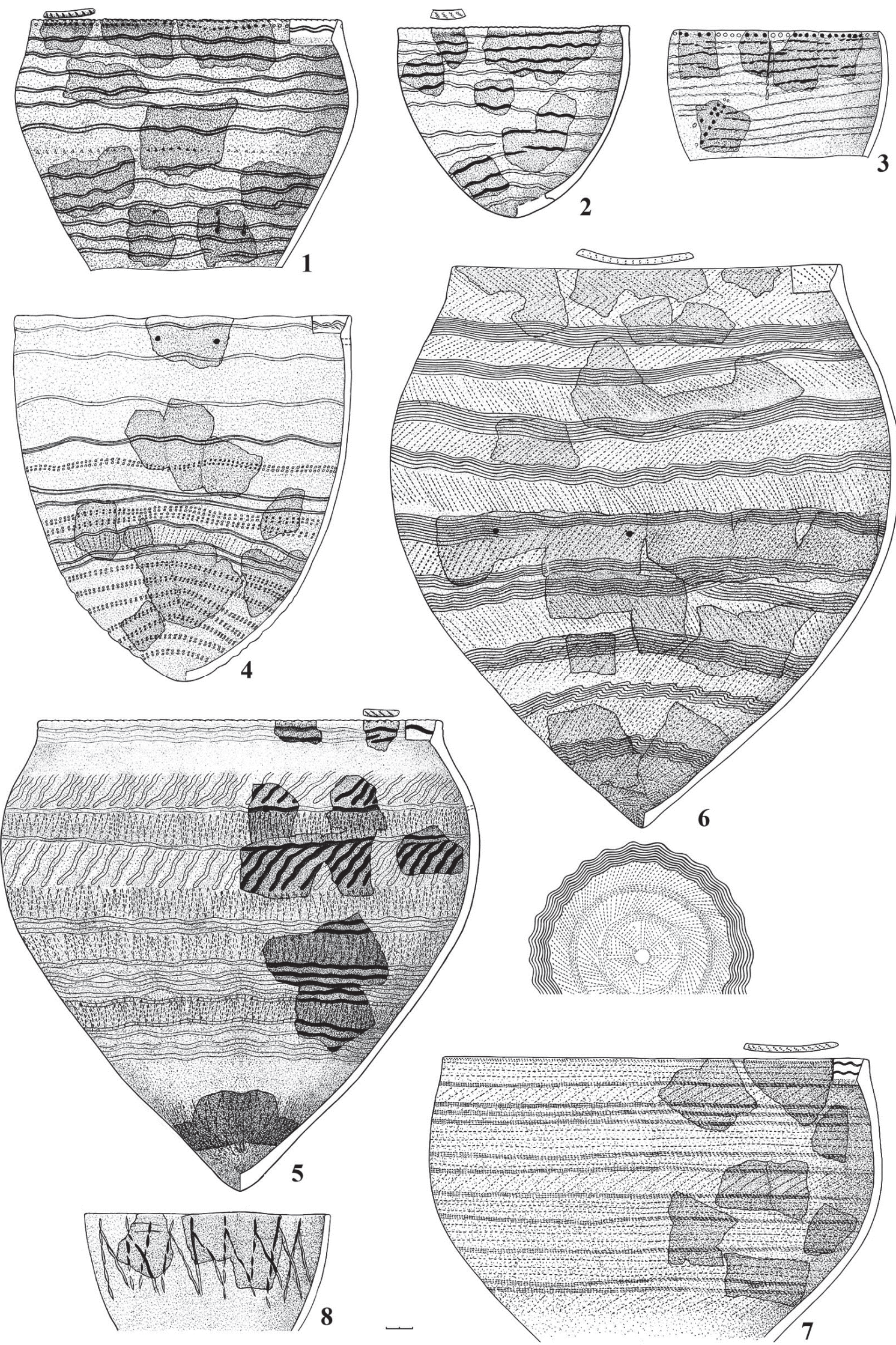

Рисунок 2 - Керамика неолитического комплекса стоянки Кедровый мыс-1 
Заключение. В результате исследований стоянки Кедровый мыс-1 были получены новые, принципиально важные результаты. Во-первых, была отработана методика одновременной разборки культурного слоя по всей площади стоянки только мелким шанцевым инструментом без употребления лопат и за счет этого снятие культурных отложений практически без метрических горизонтов, слоями в несколько миллиметров. Примененная методика позволила понять характер залегания различных хронологических комплексов и связать их с определенными почвенными горизонтами. Во-вторых, исходя из этого, были выделены неразрушенные участки неолитического культурного слоя, чего ранее не удавалось достичь при раскопках озерных стоянок Зауралья. В-третьих, получен комплекс каменного инвентаря и керамики позднего неолита классической для Зауралья полуденской традиции, ранее выделявшейся большей частью типологическим методом и не связанной с конкретным набором каменного инвентаря.

\section{СПИСОК ЛИТЕРАТУРЫ:}

1. Ковалева В.Т. Неолит Среднего Зауралья. Свердловск. Издательство УрГУ, 1989. 82 с.

2. Мосин В.С. Стоянка Шатанов 3 на озере Иртяш (классификационный и археолого-исторический подходы). Челябинск: ЦИКР «Рифей», 2011. 108 с.

3. Кернер В.Ф. Поселение Исетское Правобережное // Неолитические памятники Урала. Свердловск: УрО АН СССР, 1991. С. 46-67.

4. Петрин В.Т., Нохрина Т.И., Шорин А.Ф. Археологические памятники Аргазинского водохранилища (эпохи камня и бронзы). Новосибирск: ВО «Наука». Сибирская издательская фирма, 1993. 212 с.

5. Ковда В.А, Розанов Б.Г. (ред.). Почвоведение. Ч. 2. Типы почв, их география и использование. М.: Высшая школа, $1988.368 \mathrm{c}$.

6. Мосин В.С., Никольский В.Ю. Кремень и яшма в материальной культуре населения каменного века Южного Урала. Екатеринбург: УрО РАН, 2008. 196 с.
7. Крижевская Л.Я. Неолит Южного Зауралья. Л.: Наука, 1968. 182 с.

8. Древняя история Южного Зауралья / сер. Этногенез уральских народов. Челябинск: изд-во ЮУрГУ, 2000. T. $1.531 \mathrm{c}$.

9. Ковалева В.Т., Зырянова С.Ю. Продолжение дискуссии о Зауральском неолите // Вопросы археологии Урала. Вып. 25. Екатеринбург-Сургут: Магеллан, 2008. С. 30-43.

10. Герасименко А.А. Характеристика керамики поселения Евстюниха I // Вопросы археологии Урала. Вып. 25. Екатеринбург-Сургут: Магеллан, 2008. C. 44-72.

11. Бунькова (Герасименко) А.А. Керамика из жилища I поселения Полуденка I // Вопросы археологии Урала. Вып. 26. Екатеринбург-Сургут: Магеллан, 2011. C. $125-140$

12. Выборнов А.А., Мосин В.С., Епимахов А.В. Хронология уральского неолита // Археология, этнография и антропология Евразии. 2014. 1(57). C. $33-48$.

13. Ковалева В.Т., Зырянова С.Ю. Неолит Среднего Зауралья: Боборыкинская культура. Екатеринбург: Центр «Учебная книга», 2010. 308 с.

14. Мосин В.С. Этнокультурные процессы на Урале в начале голоцена // Вестник Южно-Уральского государственного университета. Серия «Социальногуманитарные науки». 2010. № 28 (204). Вып. 15. C. 44-49.

15. Мосин В.С. Единство жизненного пространства населения неолита-энеолита в различных природно-ландшафтных зонах Зауралья // Наука ЮУрГУ: материалы 66-й научной конференции, секции социально-гуманитарных наук. Челябинск, 2014. C. $880-886$.

Исследование выполнено при финансовой поддержке РФФИ в рамках проекта «Радиоуглеродная хронология евразийской лесостепи в неолите и энеолите» № 14-06-00041.

\section{NEOLITHIC COMPLEX OF KEDROVIY MYS-1 SITE}

V.S. Mosin, doctor of historical sciences, director South-Ural Branch of Institute of History and Archaeology of Ural Branch of the Russian Academy of Sciences, Chelyabinsk (Russia)

E.S. Yakovleva, researcher

Archaeological Research Center, Chelyabinsk (Russia)

Abstract. The paper contains the preliminary study results of multilayer site Kedroviy mys-1 on Lake Small Miassovo in the Southern Trans-Urals. The site which is a non-durable habitat of ancient population is fully investigated. No construction is revealed, but approximate contours of dwellings, probably of easy construction type of tepee with no trace were found by a planigraphy method. In the complex of finds which represents the era of stone and metal a group of artifacts of the Neolithic period in the history was found, the cultural identity and the relative chronology of the complex were established. Vessels of kozlovskaya, poludenskaya and boborykinskaya traditions were reconstructed, hence new data have been added to the complex of sources of the accumulated materials of Trans-Ural Neolithic, as it remains an urgent task for the Southern Trans-Urals, more sparsely represented by ceramics, and especially archaeologically intact vessels, compared with adjacent territories. The authors consider some methodological aspects of field research related to an attempt to highlight the stratigraphic and planigraphic intact of Neolithic layer that because of specific geomorphological conditions of the region is traditionally among the most difficult tasks of archaeological research in the mountain-forest zone of South Ural.

Keywords: South Trans-Ural; mountain-forest zone; Neolith; site; Kedroviy mys-1; stone tools; plate industry; ceramics; vessels; kozlovskaya tradition; poludenskaya tradition; boborykinskaya tradition; morphology; ornamentation; stratigraphy; planigraphy; methods; fieldwork. 